\title{
Concentração da solução nutritiva no crescimento da planta, na produtividade e na qualidade de frutas do morangueiro
}

\author{
Nutrient solution concentration on plant growth, fruit yield and quality of strawberry crop
}

\author{
Jerônimo Luiz Andriolo $^{\mathrm{I} *}$ Djeimi Isabel Jänisch ${ }^{\mathrm{I}}$ Odair José Schmitt ${ }^{\mathrm{I}}$ \\ Marcos André Braz Vaz ${ }^{\mathrm{I}}$ Francieli Lima Cardoso' ${ }^{\mathrm{I}}$ Lígia Erpen $^{\mathrm{I}}$
}

\section{RESUMO}

O objetivo do trabalho foi determinar o efeito da concentração da solução nutritiva no crescimento da planta, na produtividade e na qualidade das frutas do morangueiro cultivado em sistema fechado de cultivo sem solo. Os tratamentos consistiram de cinco soluções nutritivas com condutividades elétricas (CE) de 0,9; 1,8; 2,5; 3,2 e 3,8dS m-1 no delineamento experimental inteiramente casualizado, com três repetições. Foram determinados os seguintes parâmetros: a produtividade e a qualidade das frutas durante o período de produção e o crescimento da parte aérea e das raízes ao final do experimento. A produtividade, o tamanho das frutas e o crescimento da planta diminuíram com o aumento da concentração da solução nutritiva, enquanto a acidez titulável e o teor de sólidos solúveis totais aumentaram. A solução nutritiva com CE de 0,9dS $\mathrm{m}^{-1}$ reduz o crescimento da planta e maximiza a produtividade de frutas no cultivo sem solo do morangueiro, em sistema fechado.

Palavras-chave: Fragaria x ananassa, substrato, hidroponia, salinidade.

\section{ABSTRACT}

The objective of the research was to determine the effect of nutrient solution concentration on plant growth, fruit yield and quality of the strawberry crop grown in a closed hydroponic growing system. Treatments were five nutrient solutions at electrical conductivities (EC) of $0.9 ; 1.8 ; 2.5 ; 3.2$ and $3.8 d S \mathrm{~m}^{-1}$, in a randomised experimental design with three replications. Fruit yield and quality during the harvest period and shoot and root growth at the end of the experiment were determined. Fruit yield, fruit size and plant growth were reduced by increasing nutrient solution concentration, whereas titratable acidity and total soluble solids were increased. The EC of $0.9 d S \mathrm{~m}^{-1}$ reduces plant growth and maximizes fruit yield of the strawberry crop in the closed soilless growing system.
Key words: Fragaria $x$ ananassa, substrate, hydroponics, salinity.

\section{INTRODUÇÃO}

O cultivo sem solo do morangueiro está em expansão no Brasil. As principais razões que estimulam a mudança do cultivo tradicional no solo para sistemas sem solo são a proibição do uso do brometo de metila no controle das doenças radiculares e as dificuldades ergonométricas em manejar a cultura e colher as frutas rentes ao solo. Vantagens adicionais são a maior produtividade e a qualidade da fruta em um ciclo de produção que pode se estender durante o ano inteiro (MORAES \& FURLANI, 1999; ANTUNES \& DUARTE FILHO, 2003; LIETEN et al., 2004).

No Brasil, vêm sendo empregados, na produção do morangueiro, sistemas hidropônicos fechados do tipo Nutrient Film Technique (NFT) (MORAES \& FURLANI, 1999) ou abertos com uso de substratos orgânicos, principalmente a casca de arroz (FERNANDES-JÚNIOR et al., 2002; ANTUNES \& DUARTE FILHO, 2003). O interesse por sistemas que empregam substratos tem aumentado nos últimos anos, com o objetivo de reduzir o número de fertirrigações e, conseqüentemente, o consumo de energia elétrica. Entretanto, os sistemas abertos têm forte caráter poluente e deverão ser em breve convertidos para sistemas fechados por razões de preservação ambiental.

'Departamento de Fitotecnia, Centro de Ciências Rurais (CCR), Universidade Federal de Santa Maria (UFSM). Av. Roraima, Bairro Camobi, 97105-900, Santa Maria, RS, Brasil. E-mail: andriolo@smail.ufsm.br. *Autor para correspondência. 
Sistemas fechados que empregam substratos minerais ou orgânicos e tem reduzido consumo de energia elétrica têm sido desenvolvidos para a produção de minitubérculos de batata (ANDRIOLO, 2006) e mais recentemente para a produção de mudas e de frutas do morangueiro (ANDRIOLO, 2007).

Diversas formulações de soluções nutritivas para o cultivo sem solo do morangueiro foram descritas na literatura (GIMENEZ et al., 2008). No Brasil, predominam aquelas de MORAES \& FURLANI (1999) e de FURLANI \& FERNANDES-JÚNIOR (2004). Os limites de condutividade elétrica (CE) dessas soluções têm se situado entre 1,4 e 1,8dS m ${ }^{-1}$, considerados como aqueles mais favoráveis à produtividade e à qualidade das frutas (LIETEN, 1998; PARANJPE et al., 2003). Entretanto, resultados da literatura mostram que tanto a produtividade como a qualidade das frutas é afetada pela concentração da solução nutritiva. A produtividade e o tamanho das frutas são aumentados com valores abaixo de $1,4 \mathrm{dS} \mathrm{m}^{-1}$, enquanto a qualidade é favorecida com valores entre 2 e $8 \mathrm{dS} \mathrm{m}$ m $^{-1}$ (LIETEN, 1998).

O efeito da concentração da solução nutritiva sobre o crescimento da planta, a produtividade e a qualidade das frutas é influenciado também pelas condições ambientais. A concentração elevada da solução nutritiva dificulta a absorção de água pelas plantas, agravando os efeitos negativos do estresse hídrico sobre o crescimento e a produtividade. Por outro lado, baixas concentrações de solução nutritiva combinadas com condições ambientais de reduzida demanda evaporativa da atmosfera diminuem tanto o teor de massa seca como a qualidade da produção (LORENZO et al., 2003). No cultivo sem solo do morangueiro, tem sido sugerido modular a composição e a concentração da solução nutritiva ao longo do ano, de forma a ajustá-la ao ambiente e à demanda de nutrientes da planta em cada fase de desenvolvimento da cultura (SARROOSHI \& CRESSWEL, 1994; TAGLIAVINI et al., 2005). São escassos no Brasil resultados de estudos acerca do efeito da concentração da solução nutritiva sobre a produtividade e a qualidade das frutas do morangueiro.

O objetivo deste trabalho foi determinar o efeito de concentrações da solução nutritiva sobre o crescimento da planta, a produtividade e a qualidade das frutas do morangueiro cultivado em sistema fechado de cultivo sem solo.

\section{MATERIAL E MÉTODOS}

O experimento foi conduzido no Departamento de Fitotecnia da Universidade Federal de Santa Maria (UFSM), no interior de um abrigo de
$200 \mathrm{~m}^{2}$, coberto com polietileno de baixa densidade de $150 \mu \mathrm{m}$ de espessura e revestido lateralmente com tela antiinsetos. As unidades experimentais foram formadas por telhas de fibrocimento com 3,60m de comprimento, $1,10 \mathrm{~m}$ de largura, canais de $0,06 \mathrm{~m}$ de altura e $0,18 \mathrm{~m}$ de distância entre os canais. Cada telha foi apoiada sobre suportes a $0,80 \mathrm{~m}$ de altura do solo, com declividade de $1 \%$, e a superfície foi revestida com filme transparente de polietileno de baixa densidade com espessura de $100 \mu \mathrm{m}$. Os canais foram preenchidos com brita basáltica média, de tamanho de partículas entre 0,015m e 0,020m. Sobre a brita foi colocada uma tela plástica de 20 mesh (tela antiinseto) e sobre a tela uma camada de $0,15 \mathrm{~m}$ de areia média, como substrato para o crescimento das raízes das plantas. As características físicas da areia foram determinadas no Laboratório de Física do Solo da UFSM, indicando granulometria entre 0,001 e 0,003m, densidade aparente de $1.608,6 \mathrm{~g} \mathrm{dm}^{-3}$ e capacidade de retenção de água de $198,6 \mathrm{~mL} \mathrm{dm}^{-3}$. Um reservatório de fibra de vidro com capacidade para 500L foi instalado próximo à extremidade inferior das telhas para armazenar a solução nutritiva, sendo que mais informações acerca da instalação e do funcionamento do dispositivo hidropônico podem ser encontradas em ANDRIOLO (2007).

A formulação da solução nutritiva foi ajustada com base na formulação proposta por FURLANI \& FERNANDES JÚNIOR (2004), modificada para atingir relações iônicas $\mathrm{NO}_{3}{ }^{-} / \mathrm{K}^{+}$de 1,4 e $\mathrm{K}^{+} /$ $\left(\mathrm{Ca}^{2+}+\mathrm{Mg}^{2+}\right)$ de 1,1 e somatório iônico de 14,2meq $\mathrm{L}^{-1}$. Essa solução nutritiva foi empregada como testemunha, com concentrações de (em mmol L $\left.{ }^{-1}\right): 10,2$ de $\mathrm{NO}_{3}{ }^{-} ; 2$ de $\mathrm{H}_{2} \mathrm{PO}_{4}^{-}$; 7,4 de $\mathrm{K}^{+}$; 2,4 de $\mathrm{Ca}^{++} ; 1$ de $\mathrm{Mg}^{++}$e 1 de $\mathrm{SO}_{4}{ }^{--}$. A condutividade elétrica foi de $1,6 \mathrm{dS} \mathrm{m} \mathrm{m}^{-1}$ e o pH de 5,7. Os micronutrientes foram fornecidos nas concentrações de (em mg L $\mathrm{m}^{-1}$ ): 0,03 de Mo; 0,42 de B; 0,06 de Cu; 0,50 de Mn; 0,22 de Zn e 1,0 de Fe. O pH foi de 5,5 e a CE de 1,6dS m${ }^{-1}$. Os fertilizantes empregados foram o nitrato de potássio $\left(\mathrm{KNO}_{3}\right)$, o nitrato de cálcio [Ca( $\left.\left(\mathrm{NO}_{3}\right)_{2}\right]$ (calcinit), o monofosfato de potássio $\left(\mathrm{KH}_{2} \mathrm{PO}_{4}\right)$ e o sulfato de magnésio $\left(\mathrm{MgSO}_{4}\right)$. O cálculo das relações iônicas entre os macronutrientes e das quantidades de sais micronutrientes foi feito de acordo com a metodologia descrita por ANDRIOLO (1999). Os tratamentos foram constituídos por concentrações múltiplas dos macronutrientes da solução nutritiva descrita anteriormente de forma a serem obtidos valores de condutividade elétrica de 0,9 (T1); 1,6 (T2, testemunha); 2,3 (T3); 3,0 (T4) e 3,7dS m ${ }^{-1}$ (T5). O delineamento experimental empregado foi inteiramente casualizado com três repetições, senda cada parcela composta por uma unidade do dispositivo hidropônico. 
A CE foi medida diariamente e corrigida quando os valores situaram-se acima ou abaixo de $10 \%$ do valor original, mediante adição de água ou de volumes complementares de solução nutritiva. $\mathrm{O}$ pH também foi medido diariamente e corrigido sempre que um desvio de 0,2 unidade foi observado, mediante adição de soluções $1 \mathrm{~N}$ de $\mathrm{H}_{3} \mathrm{PO}_{4}$ ou $\mathrm{KOH}$, com volumes estimados a partir de uma curva de titulação previamente ajustada no laboratório. Volumes complementares de solução nutritiva preparada de acordo com a composição original de cada tratamento foram adicionados sempre que o volume medido no reservatório foi igual ou inferior a 50\% do volume original. Para tal, uma relação linear foi previamente ajustada entre a altura da coluna líquida e o volume contido no reservatório. Nenhum descarte de solução nutritiva foi feito durante o período experimental.

A freqüência das fertirrigações foi estimada com base na capacidade de retenção de água do substrato e na transpiração potencial da cultura, de forma a fornecer diariamente volumes de água superiores àqueles transpirados, com um coeficiente de drenagem igual ou superior a 30\%. A transpiração potencial foi estimada a partir da radiação solar global incidente no topo da cobertura vegetal e da área foliar da cultura (HENNION \& VESCHAMBRE, 1997), com base em dados de literatura sobre determinações similares feitas em hortaliças cultivadas no mesmo local e ambiente (DALSASSO et al., 1997; DALMAGO et al., 2006). Por meio dessa estimativa, foram programadas quatro fertirrigações diárias de $15 \mathrm{~min}$, às $9 \mathrm{~h}, 11 \mathrm{~h}, 13 \mathrm{~h}$ e 16h30min, controladas por um programador horário.

O plantio foi realizado no dia 5 de maio, na densidade de 12 plantas $\mathrm{m}^{-2}$, e o experimento foi encerrado em 23 de novembro de 2007. Foram empregadas mudas produzidas em bandejas de poliestireno de 128 células, obtidas a partir de pontas de estolões da cultivar 'Arazá', de origem uruguaia. A condução e o manejo da cultura foram efetuados de acordo com as indicações técnicas de ANTUNES \& DUARTE FILHO (2003). As colheitas foram realizadas duas vezes por semana, na fase de maturação completa com a epiderme totalmente vermelha, correspondente ao estádio fenológico 87 (MEIER et al., 1994). As frutas colhidas foram pesadas e conduzidas ao laboratório de pós-colheita do mesmo departamento, para determinar a firmeza com penetrômetro de ponteira de 10mm, acidez titulável e teor de sólidos solúveis totais por refratometria (AOAC, 1990). Em cada colheita foi determinada a massa seca de uma amostra de $100 \mathrm{~g}$ de frutas de cada tratamento, por meio da secagem da amostra em estufa de circulação forçada de ar, na temperatura de $65^{\circ} \mathrm{C}$, até obtenção de massa constante entre duas determinações consecutivas. Uma relação foi ajustada entre a massa fresca e a massa seca em cada colheita, a qual foi empregada para estimar a massa seca total de cada colheita. Ao final do período experimental, também foram coletadas quatro plantas de cada tratamento para determinação da massa seca dos órgãos da parte aérea. A área foliar específica (SLA) de cada planta coletada foi determinada por meio da massa seca de 30 discos de $10 \times 10^{-4} \mathrm{~m}^{-2}$ de diâmetro. Uma relação foi estabelecida entre a massa seca e a superfície dos discos, a qual foi empregada para estimar o índice de área foliar (IAF) da planta. Os resultados foram submetidos à análise de variância e as variáveis com diferenças significativas determinadas pelo teste F foram submetidas à análise de regressão polinomial. Foram retidas as equações de menor grau e de maior coeficiente de determinação, sem diferenças significativas com aquelas de maior grau a $5 \%$ de probabilidade de erro.

\section{RESULTADOS E DISCUSSÃO}

Os valores diários da condutividade elétrica nos cinco tratamentos apresentaram flutuações. As médias durante todo o período experimental foram de 0,9; 1,8; 2,5; 3,2 e 3,8dS m em T1, T2, T3, T4 e T5, respectivamente. Essas variações são atribuídas às dinâmicas de absorção de água e nutrientes. A absorção de nutrientes necessária ao crescimento das plantas reduz a concentração da solução nutritiva, enquanto a absorção de água aumenta essa concentração. As diferentes concentrações empregadas como tratamentos modificam o acúmulo de massa seca das plantas e também o crescimento da área foliar. Aárea foliar é uma das variáveis que modifica a demanda de água da planta por unidade de radiação solar incidente. O processo de absorção de água e nutrientes é afetado de forma diferenciada pelo crescimento da planta e pelas variáveis ambientais que modificam também a concentração da solução nutritiva.

As produtividades total e precoce de frutas decresceram com o aumento da concentração da solução nutritiva, seguindo tendência polinomial e linear, respectivamente (Figura 1A). O maior valor de produtividade total foi equivalente a $6,8 \mathrm{~kg} \mathrm{~m}^{-2}$, em T1, com redução de $38 \%$ em T5. Resultado semelhante foi observado na massa média das frutas, com redução de 27\% de T1 para T5 (Figura 1A). Entretanto, a qualidade das frutas aumentou com a concentração da solução nutritiva (Figura 1B). O teor de sólidos solúveis aumentou $28 \%$, passando de 8,7 a $11,5^{\circ}$ Brix. A acidez titulável aumentou 31\%, passando de 4,8 a $6,2 \mathrm{meq}$ $100 \mathrm{~mL}^{-1}$. A firmeza das frutas não foi afetada 


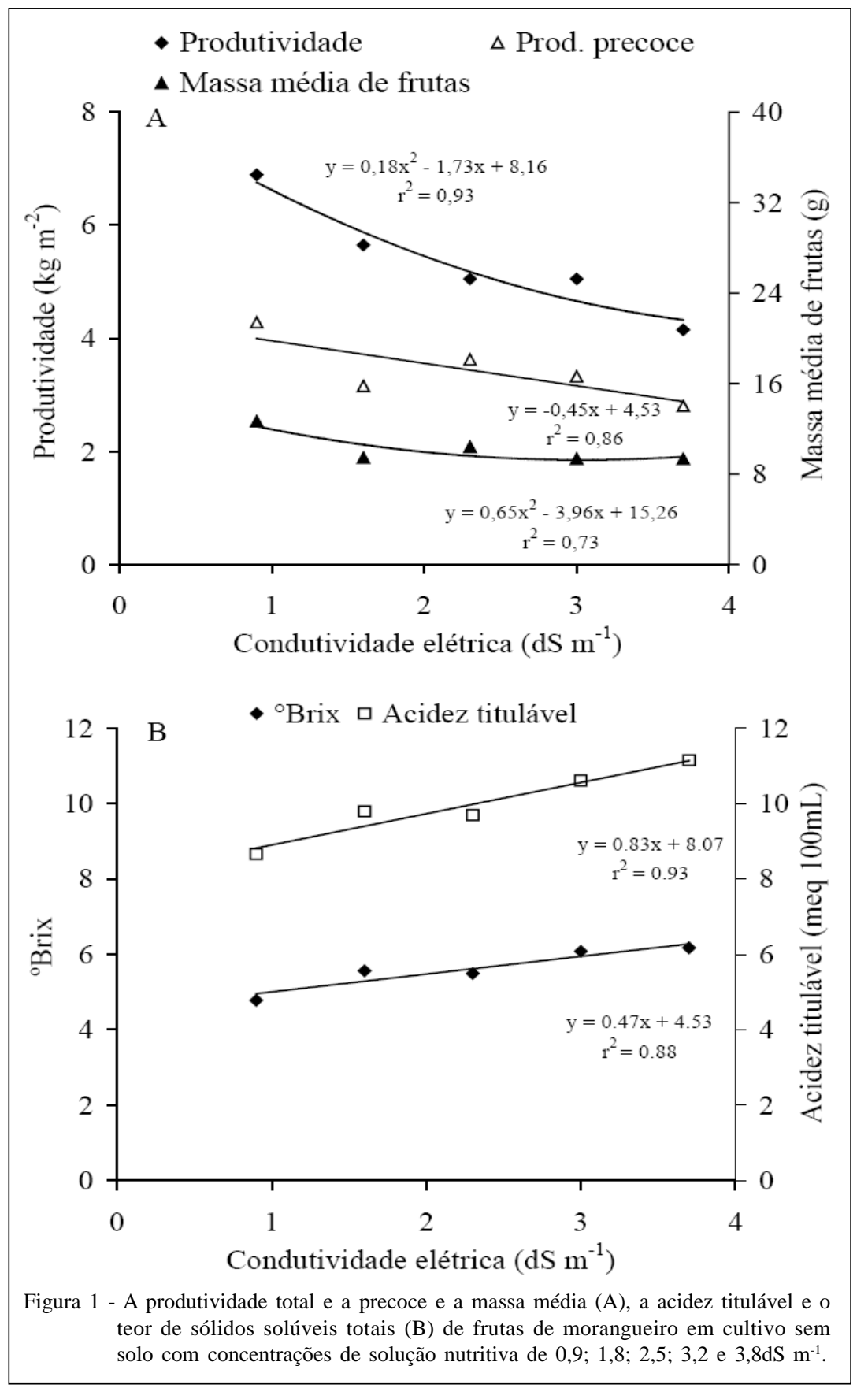

significativamente pelos tratamentos, com valor médio de $1,38 \mathrm{~N}$. O índice de área foliar seguiu tendência polinomial (Figura 2A), com valor mais elevado estimado em $1,64 \mathrm{~m}^{2} \mathrm{~m}^{-2}$ na CE de $1,0 \mathrm{dS} \mathrm{m}^{-1}$ e mais baixo de $0,58 \mathrm{~m}^{2} \mathrm{~m}^{-2}$ em $\mathrm{T} 5$, atingindo uma redução percentual de $64,6 \%$. O crescimento das plantas também decresceu com o aumento da condutividade elétrica, seguindo tendência polinomial. A massa seca total mais elevada foi estimada em 43,12g planta $^{-1}$ na CE de $0,9 \mathrm{dS} \mathrm{m} \mathrm{m}^{-1}$, decrescendo 22,2\% até o valor de 33,54g planta $^{-1}$ em T5 (Figura 1B). Tendência semelhante foi observada na massa seca vegetativa formada por pecíolos, limbos foliares, coroa e raízes com valor mais elevado estimado em 15,94g planta ${ }^{-1}$ na CE de 1,4dS m${ }^{-1}$, decrescendo $38,8 \%$ até o valor de 9,7 g lanta $^{-1}$ em T5. Não foram observadas diferenças significativas no crescimento da coroa e das raízes, com valores médios de 1,72 e $1,3 \mathrm{~g}$ planta $^{-1}$, respectivamente. O número de frutas não 


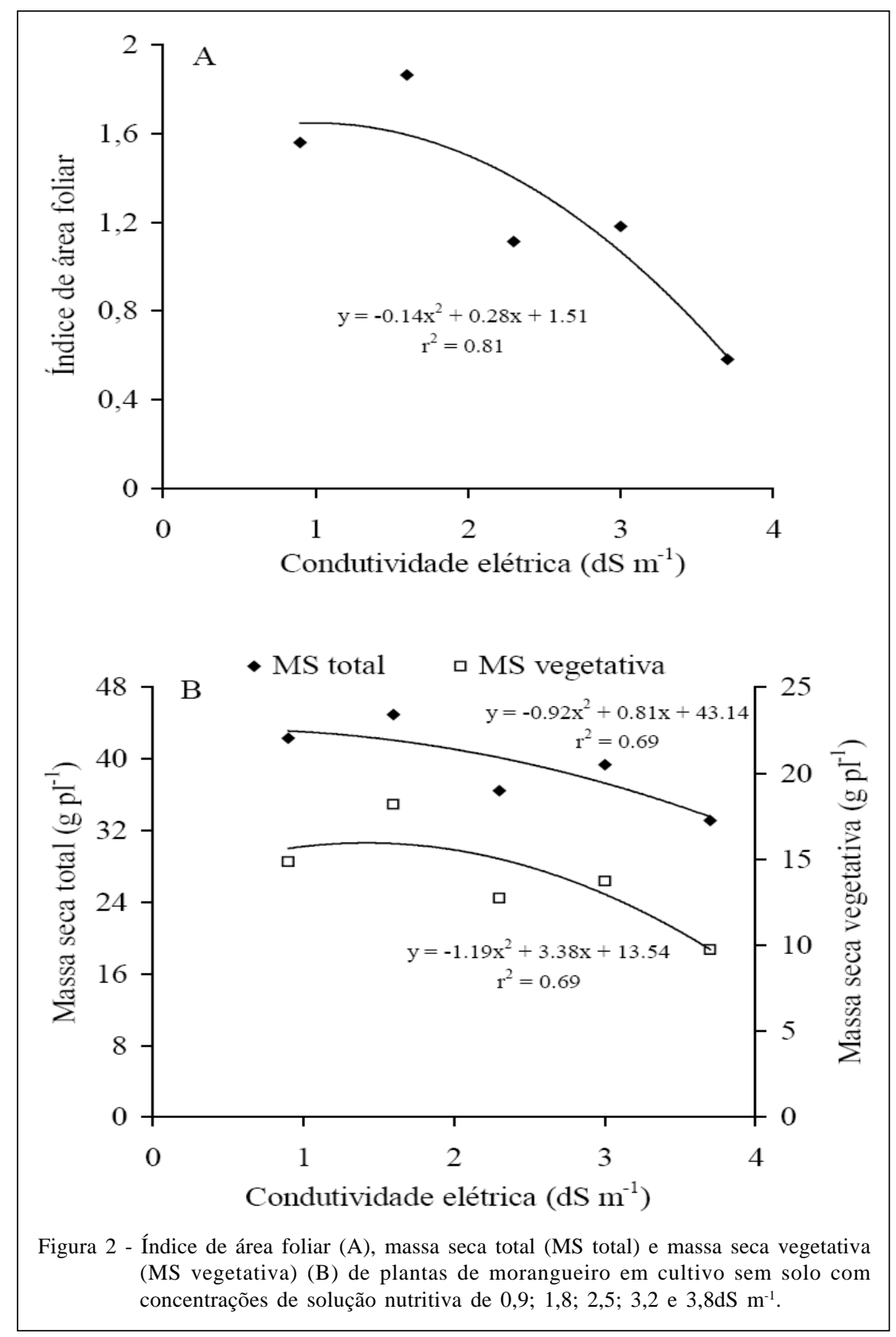

apresentou diferenças significativas entre os tratamentos e o valor médio foi de 43 frutas por planta. Na classificação da tolerância das hortaliças à salinidade feita por SHANONN \& GRIEVE (1999), aparecem o nabo, a alcachofra e a cenoura como as espécies mais sensíveis. Níveis de CE em torno das raízes próximos a $1 \mathrm{dS} \mathrm{m}^{-1}$ seriam suficientes para diminuir a produtividade dessas espécies. O morangueiro não aparece nessa classificação. Os resultados atuais sugerem quer o morangueiro estaria próximo da categoria das espécies mais sensíveis à salinidade, pois a maior produtividade de frutas foi obtida na CE de $0,9 \mathrm{dS} \mathrm{m}^{-1}$. Esse valor é $55 \%$ inferior ao limite de tolerância de 2,0dS $\mathrm{m}^{-1}$ estimado por ANDRIOLO et al. (2005), para a alface cultivada no mesmo local e em condições similares.

Os resultados do crescimento das plantas (Figura 2) indicaram que a área foliar foi drasticamente reduzida pelo aumento da CE da solução nutritiva. Essa observação confirma os resultados descritos na literatura para outras hortaliças (LORENZO et al., 2003; ANDRIOLO et al., 2005; MULLER et al., 2007). Entretanto, a figura 2 mostra que o maior crescimento das plantas ocorreu na CE de $1,4 \mathrm{dS} \mathrm{m}^{-1}$, sugerindo que

Ciência Rural, v.39, n.3, mai-jun, 2009. 
a produtividade de frutas não estaria necessariamente associada ao maior crescimento vegetativo das plantas. A produtividade de frutas do morangueiro é um processo que depende, entre outros fatores, da precocidade da floração, da taxa de emissão de inflorescências e da partição da massa seca entre a parte vegetativa e as frutas. É provável que uma maior disponibilidade de nutrientes, especialmente o $\mathrm{N}$, decorrente da maior concentração da solução nutritiva de T2 em relação àquela de T1, tenha favorecido o crescimento vegetativo e retardado a floração, de forma semelhante às observações feitas em outras hortaliças como a batata (BÉLANGER et al., 2001; PAULA, 2005) e o meloeiro (FOGAÇA et al., 2007). Os resultados indicam a necessidade de realização de pesquisas sobre a composição da solução nutritiva, visando definir relações entre cátions e ânions que aumentem a fração da massa seca total alocada para as frutas.

No cultivo sem solo do morangueiro, são indicados valores de CE em torno de $1,4 \mathrm{dS} \mathrm{m}^{-1}$ para obtenção de alta produtividade e qualidade das frutas (LIETEN, 1998; PARANJPE et al., 2003). Os resultados atuais indicam que valores próximos de $1,0 \mathrm{dS} \mathrm{m}{ }^{-1}$ podem ser empregados para maximizar a produtividade e o tamanho dos frutos. Uma das hipóteses que pode ser apontada para explicar esse resultado é o volume de substrato disponível para o crescimento das raízes. Em sistemas de cultivo sem solo que empregam substratos, volumes em torno de $1,4 \mathrm{dm}^{3}$ planta $^{-1}$ (SARROOSHI \& CRESSWEL, 1994) ou 2,24dm ${ }^{3}$ planta $^{-1}$ (FERNANDES JÚNIOR et al., 2002) têm sido empregados. Esses volumes são respectivamente 88,7\% e 81,2\% inferiores ao volume de areia disponível para cada planta no atual experimento, que foi de $12,4 \mathrm{dm}^{3}$ planta $^{-1}$. É possível que o maior volume de substrato disponível para o crescimento das raízes tenha compensado a menor concentração de nutrientes na solução nutritiva. Esse é o caso das plantas cultivadas no solo, cujas raízes podem explorar volumes maiores do que no cultivo sem solo, atingindo níveis de produtividade elevados mesmo com concentrações de nutrientes menores do que aquelas empregadas nas soluções nutritivas. Essa característica do atual sistema hidropônico seria também uma das explicações para a elevada produtividade de $574 \mathrm{~g} \mathrm{planta}^{-1}$, maior do que aquela de 310 g planta $^{-1}$ obtida por SARROOSHI \& CRESSWEL (1994) em lã de rocha e de 364,5g planta ${ }^{-1}$ obtida em NFT por FERNANDES JÚNIOR et al. (2002).

A qualidade das frutas apresentou valores do teor de sólidos solúveis totais entre os limites de 4,8 e $6,2^{\circ}$ Brix e da acidez titulável entre 8,7 e $11,1 \mathrm{meq}$ $100 \mathrm{~mL}^{-1}$ entre os cinco tratamentos (Figura 1B). O valor mais elevado do teor de sólidos solúveis totais foi inferior àquele obtido por SARROOSHI \& CRESSWEL (1994), o qual se situou entre 8,5 e 9,0Brix, e também por FERNANDES JÚNIOR et al. (2002), com 7,7º Brix. Esses resultados podem estar relacionados com as variáveis ambientais radiação solar, temperatura e umidade do ar durante o período de produção das frutas, as quais mudam entre as diferentes regiões e com a época do ano. Isso não significa que a melhoria da qualidade das frutas seja incompatível com o cultivo sem solo, pois outros fatores como, por exemplo, as relações entre os cátions que entram na composição da solução nutritiva, também influenciam as características de qualidade (LIETEN, 1998), os quais devem ser objetos de novas pesquisas.

O emprego de soluções nutritivas com condutividades elétricas menores que $1,4 \mathrm{dS} \mathrm{m}^{-1}$ permitiria aumentar o rendimento da cultura, mediante diminuição do custo da fertirrigação e do aumento do valor comercial, pois o tamanho da fruta é uma das características que influencia a cotação do produto. A qualidade das frutas foi inferior na CE de T1 em relação àquela de T2 (Figura 1B). Porém, enquanto a acidez diminuiu $14 \%$ e o teor de sólidos solúveis $11,5 \%$, a produtividade de T1 aumentou 22\% e o tamanho da fruta $35 \%$. Conclui-se que as perdas qualitativas são de menor magnitude que os ganhos de produtividade ao reduzir a CE. Por outro lado, os resultados atuais evidenciam a importância do manejo da solução nutritiva quando são empregados sistemas fechados de cultivo sem solo, especialmente nos períodos de elevada demanda de transpiração da cultura, para evitar que os aumentos na concentração da solução nutritiva venham a reduzir a produtividade de frutas.

\section{CONCLUSÕES}

No cultivo do morangueiro em sistema fechado de cultivo sem solo, tendo a areia como substrato, o crescimento da planta e a produtividade de frutas diminuem quando a concentração da solução nutritiva aumenta no intervalo entre 0,9 e $3,7 \mathrm{dS} \mathrm{m} \mathrm{m}^{-1}$. O teor de sólidos solúveis totais e a acidez titulável das frutas aumentam no mesmo intervalo de concentração. A solução nutritiva com CE de $0,9 \mathrm{~d} S \mathrm{~m}^{-1}$ pode ser empregada para maximizar a produtividade de frutas nesse sistema de cultivo.

\section{AGRADECIMENTOS}

Ao Conselho Nacional de Desenvolvimento Científico e Tecnológico (CNPq), pelo auxílio financeiro, processo 470177/2006-3, bolsas PQ a Jerônimo Luiz Andriolo, PIBIC-UFSM a Djeimi Isabel Jänisch e BIC-CNPq a Odair José Schmitt. À Fundação de Amparo a Pesquisa do RS (FAPERGS), pela Bolsa de Iniciação Científica a Marcos André Braz Vaz.

Ciência Rural, v.39, n.3, mai-jun, 2009. 


\section{REFERÊNCIAS}

ANDRIOLO, J.L. Fisiologia das culturas protegidas. Santa Maria: UFSM, 1999. 142p.

ANDRIOLO, J.L. et al. Growth and yield of lettuce plants under salinity. Horticultura Brasileira, v.23, p.931-934, 2005.

ANDRIOLO, J.L. Sistema hidropônico fechado com subirrigação para produção de minitubérculos de batata. In: SEMINÁRIO DE MELHORAMNETO GENÉTICO E PREVISÃO DE EPIFITIAS EM BATATA, 2006, Santa Maria, RS. Anais... Santa Maria: UFSM, CCR, Departamento de Fitotecnia, 2007. p.26-40.

ANDRIOLO, J.L. Preparo e manejo da solução nutritiva na produção de mudas e de frutas do morangueiro. In: SEMINÁRIO SOBRE O CULTIVO HIDRÔPONICO DE MORANGUEIRO, 2007, Santa Maria, RS. Anais... Santa Maria: UFSM, CCR, Departamento de Fitotecnia, 2007. 60p. p.41-50.

ANTUNES, L.E.C.; DUARTE F.J. Produção de mudas de morango. In: SANTOS, A.M. dos; MEDEIROS, A.R.M. (Ed.). Sistema de produção do morango. Sistemas de produção, 5. Pelotas: EMBRAPA CT, 2003. Capturado em 24 mar. 2006. Online. Disponível em: <http;//www.cpact.embrapa/ sistema/ morango $>$.

ASSOCIATION OF OFFICIAL ANALYTICAL CHEMISTS. Official methods of analysis of the Association of Official Analytical Chemists. 15.ed. Arlington, 1990. 1298p.

BÉLANGER, G.W., JR et al. Critical nitrogen curve and nitrogen nutrition index for potato in eastern Canada. American Journal of Potato Research, v.78, p.355-364, 2001.

DALMAGO, G.A. et al. Evapotranspiração máxima da cultura do pimentão em estufa plástica em função da radiação solar, temperatura, umidade do ar e déficit de saturação do ar. Revista Brasileira de Agrometeorologia, v.36, n.3, p.785-792, 2006.

DALSASSO, L.C.M. et al. Consumo de água do tomateiro tipo salada em estufa plástica. Revista Brasileira de Agrometeorologia, v.5, n.1, p.61-67, 1997.

FERNANDES-JÚNIOR, F. et al. Produção de frutos e estolhos do morangueiro em diferentes sistemas de cultivo em ambiente protegido. Bragantia, v.61, n.1, p.25-34, 2002. Disponível em: <http:// www.scielo.br/scielo.php?script $=$ sci_arttext\&pid=S000687052002000100005\&lng=en\&nrm=iso\&tlng=pt $>$. Doi: 10.1590/ S0006-87052002000100005.

FOGAÇA, M.A. de F. et al. Concentração de nitrogênio na solução nutritiva na produtividade e qualidade de frutos de melão cultivado em substrato. Ciência Rural, v.37, p.72-78, 2007. Disponível em: $<$ http://www.scielo.br/scielo.php?script=sci_arttext\&pid=S010384782007000100012\&lng=pt\&nrm=iso\&tlng=pt>. Doi: 10.1590/ S0103-84782007000100012.

FURLANI, P.R.; FERNANDEZ JÚNIOR, F. Cultivo hidropônico de morango em ambiente protegido. In: SIMPÓSIO NACIONAL DO MORANGO \& ENCONTRO DE PEQUENAS FRUTAS E FRUTAS NATIVAS DO MERCOSUL, 2., 2004, Pelotas. Anais... Pelotas: Corrêa Antunez, L.E. et al. (Ed.). EMBRAPA, 2004. p.102-115. (Documentos 124).
GIMENEZ, G. et al. Cultivo sem solo no morangueiro. Ciência Rural, v.38, n.1, p.273-279, 2008. Disponível em: <http:// www.scielo.br/scielo.php?script $=$ sci_arttext\&pid $=$ S0103$84782008000100048 \& \operatorname{lng}=$ en \&nrm=iso\&tlng=pt $>$. Doi: $10.1590 /$ S0103-84782008000100048.

HENNION, B.; VESCHAMBRE, D. La fraise: maîtrise de la production. Paris: CTIFL, 1997. 299p.

LIETEN, P. et al. Recent situation of strawberry substrate culture in Europe. Acta Horticulturae. (ISHS) v.649, p.193196, 2004.

LIETEN, F. La fragola in Belgio-Olanda. In: FAEDI, W. (Ed.). La fragola verso il 2000. Convegno Nazionale. Verona: Camera di Commercio Industria Artigianato e Agricultura, 1998. p.83-94.

LORENZO, P. et al. External greenhouse mobile shading: effect on microclimate, water use efficiency and yield of a tomato crop grown under different salinity levels of the nutrient solution. In: PARDOSSI, A. et al. (Ed.). Managing greenhouse crops in saline environment. Acta Horticulturae, v.609, p.181-186, 2003.

MEIER, U. et al. Phänologische Entwick-lungsstadien des Kernobstes (Malus domestica Borkh. und Pyrus communis L.), des Steinobstes (Prunus-Arten), der Johannisbeere (Ribes-Arten) und der Erdbeere (Fragaria $x$ ananassa Duch.). Nachrichtenbl. Deutchland Pflanzenschutzd. v.46, p.141153, 1994.

MORAES, C.A.G. de; FURLANI, P.R. Cultivo de hortaliças de frutos em hidroponia em ambiente protegido. Informe Agropecuário, v.20, n.200/201, p.105-113, 1999.

MULLER, D.R. et al. Produção hidropônica de batata em diferentes concentrações de solução nutritiva e épocas de plantio. Pesquisa Agropecuária Brasileira, v.42, n. 5, p.647-653, 2007. Disponível em: <http://www.scielo.br/ scielo.php? script = sci_art text \& pid=S 0100 204X2007000500006\&lng $=$ en\&nrm=iso\&tlng $=p t>$. Doi: 10.1590/S0100-204X2007000500006.

PARANJPE A. et al. Winter strawberry production in greenhouses using soilless substrates: an alternative to methyl bromide soil fumigation. Proceedings of the Florida State for Horticultural Science, v.116, p.98-105, 2003.

PAULA, A.L de. Acúmulo de massa seca e nitrogênio durante o crescimento e desenvolvimento da cultura da batata. 2005. 23p\f. Dissertação (Mestrado em Agronomia) - Curso de Pós-graduação em Agronomia, Universidade Federal de Santa Maria.

SAROOSHI, R.A.; CRESSWELL, G.C. Effects of hydroponic solution composition, electrical conductivity and plant spacing on yield and quality of strawberries. Australian Journal of Experimental Agriculture, v.34, p.529-535, 1994. Disponível em: <http://www.publish.csiro.au/ ?paper=EA9940529>. Doi:10.1071/EA9940529.

SHANNON, M.C.; GRIEVE, C.M. Tolerance of vegetable crops to salinity. Scientia Horticulturae, v.78, p.5-38, 1999.

TAGLIAVINI, M. et al. Dynamics of nutrients uptake by strawberry plants (Fragaria $\boldsymbol{x}$ ananassa Dutch.) grown in soil and soilless culture. European Journal of Agronomy, v.23, n.1, p.15-25, 2005. 